\title{
Exploring Leadership Effectiveness of Engineers at a Company in the Sugar Industry in South Africa
}

\author{
Mr. Dennis M. Dlamini' ${ }^{1}$ Prof. Cecile N. Gerwel Proches ${ }^{2}$ and Dr Nikita Singh ${ }^{3}$ \\ ${ }^{1,2,3}$ Graduate School of Business and Leadership, University of KwaZulu-Natal, South Africa.
}

ORCID: 0000-00002-7795-3534 (Nikita Singh)

\begin{abstract}
Employees in management positions and leadership roles including engineers - are under extreme pressure to achieve more with fewer resources. Engineers are at a critical organisational level, being the link between the general workforce and senior management. This study sought to explore the leadership effectiveness of engineers at a company in the sugar industry in South Africa. A qualitative research methodology approach, which incorporated purposive sampling and interviews was employed. Data were analyzed using thematic analysis. During the interviews, several issues that had an impact on the effectiveness of such engineers were identified, the main issue being the perception from many of the engineers that the organisation was placing very little emphasis on their role as leaders, which led them to believe that they were not recognised as leaders. The study concluded with recommendations on how to improve the leadership capabilities of the engineers to enhance their effectiveness, implying that it is currently compromised.
\end{abstract}

Keywords: Engineers, Leadership, Management, South Africa, Sugar Industry

\section{INTRODUCTION}

The company under study in the sugar industry in South Africa was hit hard with a period of drought. This adversely impacted cane crop, which translated into a massive reduction in the amount of sugar that could be produced [1]. Owing to management having no control over the rainfall patterns, and sugar manufacturing being heavily reliant on rain for raw materials, management had to concentrate on implementing serious cost-control measures and execution of effective interventions to realise attractive returns on capital. Also, owing to the nature of the business, the fixed costs element of the business remained very high; which meant that the campaign for reducing costs has had to continue throughout all the operations [2].

Employees in management and leadership roles in the company on which this research was based, found themselves subjected to extreme pressure to uplift the morale of other employees, especially since it is often found that low staff morale results in poor plant performance and low productivity [3]. Furthermore, they had only scant resources with which to accomplish the goals of the organisation. The success of each operating centre (which would ultimately culminate in the success of the organisation) was heavily dependent on the way in which each Section Engineer effectively led his team in achieving whatever performance target/s they were set.

The sugar industry in South Africa has in recent years faced many challenges as highlighted in previous research $[4,5,6,7,8,9]$. Several studies on leadership effectiveness have been conducted both globally and locally [10]. These studies highlighted the importance of effective, productive and enduring organisations and the fact that as much as these organisations can be re-organised, restructured or reengineered to achieve the desired effectiveness, such will not be sustainable unless change is built on the preeminence of the human resource (the teams and their leaders). People and processes will always be more important than tasks and organisational structure in accomplishing goals; and productivity, systems and processes are only effective if leadership within an organisation is effective [10].

Employees in management and leadership roles are under extreme pressure to achieve more with the few resources they have. Engineers fall into this category, their role being a combination of both management and leadership. Engineers are at a critical organisational level, being the link between the general workforce and senior management. The success of each operating centre in this company was heavily dependent upon the way in which each engineer led his team in achieving excellent performance on the set targets of the key performance areas. This study therefore aimed to explore the leadership effectiveness of engineers at a company in the sugar industry in South Africa.

The objectives of the study were:

- To establish the leadership effectiveness of engineers as leaders at a company in the sugar industry in South Africa;

- To identify the areas of improvement that had to be addressed with regard to the engineers' leadership capabilities, in effectively leading their sections at a company in the sugar industry in South Africa; and 
- $\quad$ To determine the way in which the leadership capabilities of engineers within a company in the sugar industry in South Africa could be developed to the standard required by the organisation.

Leadership is a diverse and complex concept that has proved to be difficult to define in one simple sentence or paragraph, there being many models and definitions provided by the literature. Allio [11] stated that leadership comes across as having many facets, dimensions, and aspects. Lopez [17] supported this notion by adding that scholars are yet to determine an absolute definition of leadership. Many of the scholars still disagree on the exact elements that comprise leadership, and on the norms or practices of leadership that one may successfully emulate [11].

McCarthy [12] argued that leadership is both a process and a property. On the one hand, the process element consists of using non-intimidating influence, whilst on the other hand the property element consists of the set of qualities ascribed to an individual that is perceived by others successfully to employ influence in accomplishing desired outcomes. With many leadership definitions in existence, McCarthy [12] contributed to the literature by simply defining it as the creative process of leading people. Green and McCann [13] added that leadership is about inspiring and motivating other people to achieve positive outcomes, and also guiding people in the desired direction whilst being exemplary in all aspects.

Similarly, leadership has been defined by Döös et al. [14] as the process of exerting influence over others to understand and agree on goals to be accomplished in a given instance; and the way in which plans leading to the accomplishment of the goals may effectively be implemented. Leadership is further defined as the process of facilitating individual and collective efforts to achieve shared objectives [14]. Leadership is a practice that an individual uses to influence other people to achieve goals, and also to channel the organisation in a manner that translates to improved integration and consistency [16]. Other important leadership traits worth mentioning are: charisma, emotional intelligence, enthusiasm, toughness, fairness, honesty, humility, and integrity and the list of these leadership traits is endless; each leader potentially having a multiplicity of traits. Spicker [16] also added another key aspect of leadership as being the leader's ability to achieve certain objectives that others could not due to the skills and knowledge possessed by the leader. The behaviour displayed by the leader is important as it predicts his or her attitude in any given situation. Lopez [17] and Singh and Bodhanya [18] added relationship as another key element - in which case the focus is on the leaderfollower relationship in a synergistic process. In addition, Allio [11] suggested that people grow into leaders as they test and try out various approaches in an effort to deal with new problems. They gradually merge the approaches that have been successful into a preferred leadership style which they practise. Ultimately, this means that to improve or gain leadership competencies and introspection, and to develop a genuine personal identity which supports a leadership role, one must experience the leadership journey.

Sharma and Jain [15] identified key leadership factors that make up the leadership process. Without any one of these leadership factors the leadership process cannot exist. There must be someone in the role of leader. It is important for this person to clearly understand himself, to clearly understand his knowledge limitations, and to clearly understand his capabilities. The success of the leader is determined by his followers, not by him or anyone else. The followers' inspiration comes from their trust and belief in their leader, having confidence in him [15]. Allio [11] pointed out that a critical collaboration must exist between the parties, that is, the leaders and the followers, when choosing a course of action. Allio [11] also pointed out that the effective implementation of the leader's agenda is dependent upon the followers' response to the leader.

Where there are leaders, there must be followers, as one cannot exist without the other [18]. Followers often come from very different backgrounds, having very different experiences, attitudes, values, and beliefs [15]. This means that the leadership styles to be utilised in leading the followers will not be identical in every case. Alkahtani [19] supported this argument, saying that a leader cannot afford to use one standard or prescribed leadership style to lead effectively. Sharma and Jain [15] added their view again by saying that this ultimately means that the leader must know and understand his followers. Lastly, the above researchers said that it was critical for the leader to possess a good comprehension of the element of human nature, which includes such aspects as emotions, motivation, and needs.

Situations in the workplace will vary widely. This means that what works in one situation will not necessarily work in another. A complex situation always exists when it comes to people and leadership situations in the work environment, and therefore the skill of being adaptable in every situation is imperative. Also, the correct judgement is crucial, in terms of deciding on the best leadership style to use in any situation [20].

There is always some controversy surrounding the relationship between leadership and management. Algahtani [21] drew attention to the fact that most people assume that all managers are leaders, and that all leaders are managers. He disputed this assumption, saying that this is fallacious because certain institutions have managers who are not involved in practising any leadership; in some organisations people perform leadership roles even though they do not hold any managerial positions. This statement upholds the notion that the controversy surrounding the differences between managers and leaders remains ongoing.

Döös et al. [14] simplified the leader-manager controversy by highlighting that, in reality, a person appointed as a manager 
within an organisation has sometimes to perform certain leadership responsibilities whilst holding the managerial position. He further asserted that leadership is therefore viewed as being an integral part of managers' duties.

According to Spicker [16], leaders are risk-takers, whereas managers would rather avoid taking risks; leadership tackles nasty problems, while management handles docile problems. Some elements of management are: execution, proper structures, efficiency, and effectiveness; whereas leadership is focused on the future, and in unknown and ambiguous conditions. Algahtani [21] added that leadership and management encompass a peculiar set of activities or functions. While similarities are shared between leaders and managers, such as influencing others by using specific powers to accomplish certain objectives, some prominent differences exist. He emphasised that leaders and managers are the backbone of an organisation, and with their roles overlapping, they should be viewed as complementary to one another. Furthermore, he stressed that strong leadership and strong management are crucial to the success of any organisation; and that its optimal effectiveness can only be realised if the two roles can co-exist. Green and McCann [13] added that organisations need good managers who will make the right decisions about resourcing and planning in generating the required outcomes and using available resources effectively. Algahtani [21] also pointed out that there must be a good balance between the roles of both management and leadership, as well as a good mix of leaders and managers, for an organisation to reap the fruits of success.

Algahtani [21] argued that being an effective leader is underpinned by certain behaviours and qualities that are common knowledge, some of them being: the mentality to serve, the ability to coach and mentor, being reliable, being an expert in certain areas, being responsible, possessing listening and communication skills, having a clear vision, being authentic, having good ability to prioritise; being honest and willing to share, as well as having self-confidence. Willcocks [22] argued that ultimately, the nub of an effective leadership style is excellent management of teams with solid emphasis on interpersonal relationships as well as tasks.

Allio [11] pointed out that effective leaders must be competent and must have integrity and commitment to their organisations. Understanding the organisational culture and the structure within which it functions is of utmost importance. Furthermore, he articulated that effective leaders address the needs of the many stakeholders with whom they are involved; they strike a good balance between economic and non-economic objectives; and they set up, as well as keep track of performance measures, be they short-term or long-term.

\section{RESEARCH METHODOLOGY}

The approach that was used for this study was a qualitative research methodology. This research methodology encompasses the exploration and comprehension of the meaning that individuals and groups attribute to a human or social problem. Typically, with such a methodology, questions and procedures emerge from the researcher, data is collected and analysed, and the researcher ascribes meanings to, and makes interpretations of, the data [23].

Purposive sampling was used in this study, as participants were selected by virtue of their positions in the organisation, or because of the knowledge they possessed on the particular subject of this study [24]. The interviews conducted were semistructured and face to face, which allowed for interaction between the researcher and the respondents. This approach also allowed for follow-up questions which helped the researcher to gain more clarity on the subject.

Twenty engineers from the five operating centres of the company were initially selected as participants in this study by virtue of their current positions in which they were expected to "lead". However, only fifteen could be interviewed, the others having personal commitments during the research period. This was recognised as an unfortunate limitation of the study. Data was analysed using a process of thematic analysis in which the raw data was grouped according to similarity in what was said by respondents, and the themes that emerged from this process were used to present results for discussion in a narrative-text format.

\section{FINDINGS AND DISCUSSION}

Several themes emerged as the data was explored and organized. Below is a description and discussion of each theme interspersed with quotes from respondents which led to the discovery of such themes. Since this was a qualitative study based on interviews, it is hoped such quotes will provide a rich narrative to justify the findings, as well as to allow the 'voice' of the respondents to shine through.

\section{II. I. Effective leadership as understood by the engineers}

The study identified that a common understanding of effective leadership existed amongst the respondents. According to their thinking, effective leadership implied that the leader led with a definite vision in mind, transforming his team and aligning them with the organisational vision. As one respondent explained:

\footnotetext{
"Effective leadership encompasses many elements, some of which include the leader's ability to be empathetic with his people's feelings and being able to create an open and trusting relationship between himself and the team members." (R2).
}

The respondents maintained that effective leadership was about leadership in which the leader empowered his team to make 
decisions, allowing them to make mistakes, learning from those mistakes.

Shekari and Nikooparvar [10] supported the above notion with their explanation that effective leadership was about motivating employees through investing in them and ensuring that they were sufficiently empowered to make the best decisions. The above-mentioned researchers continued that highly motivated and well-trained employees were the pillars of any organisation that sought effectively to achieve its goals.

The study also identified that the respondents were well aware that the call of duty for an effective leader went far beyond simply having a vision and being able to align the teams with the vision. They understood that, ultimately, there has to be a plan of action which must be effectively executed to obtain the desired outcomes. Failure to execute this plan could only mean disaster for the organisation and by extension, the desired outcomes not being achieved.

According to Shekari and Nikooparvar [10], in effective leadership, the leaders have the capability of translating purpose and vision into action; they are able to influence the workers to align with the organisational vision. These leaders are able to recognise the unique skills or talents of each worker. Such skills or talents are developed to the individual's full potential and utilised effectively for the benefit of the organisation. This statement supports the above finding.

\section{III.I I. Engineers' adjustment to different leadership styles}

The study identified that the respondents used various leadership styles in their everyday leadership roles. This supported current research on leadership which asserts that it is essential that a leader be able to identify the most appropriate leadership style that would yield the most effective results for the organisation [19], thus leaders have to be flexible enough to adapt and change their leadership style according to the needs, personalities and working styles of their subordinates.

\begin{abstract}
"This may have worked for them in the past, but they need to realise that they are now leading a very different generation and their style is no longer effective as it only causes so much stress on the subordinates. I wish they understood how much this hinders our creativity, innovation, and growth." (R13)"
\end{abstract}

The study also identified that, to a large extent, the leadership styles practised by the respondents were influenced by the kind of leadership styles that they were experiencing from their superiors; this varied from centre to centre; and, according to Ekaterini [25], for one to be authentic in his leadership style and behaviour, one has to develop one's own leadership style in accordance with one's personality and character.
From the study it was evident that the respondents predominantly used transactional, transformational and situational leadership styles. The study identified that the transactional leadership style featured mainly because of the nature of the business, it being a production environment in which compliance with many elements offered by the employees was key. According to Giltinane [20], transactional leadership offers rewards to employees in return for proper compliance with elements of the organisational strategy.

Situational leadership was also identified in the study as a further approach used by the respondents. This emerged as the most dominant style, encompassing a combination of the transactional and transformational leadership styles, as well as other leadership styles that might be brought in to be used as determined by the circumstances. The underlying factor here was that no single situation was identical with other situations in the work environment; the respondents acknowledged that they needed to deal with each situation according to its merits or requirements.

\section{I I. I I I. Unsupported leadership pipeline of engineers}

The study identified that the majority of the respondents (a percentage figure of such respondents was not provided as this was a qualitative study) believed that the organisation did not really consider them leaders in their roles as engineers. Respondents argued that this was evident even in the training programme for the Engineers in Training (EITs), in which there was very little emphasis on the importance of empowering the trainees with the necessary leadership competencies. They mentioned that the emphasis in the programme was only on the technical competency of the individual, as iterated by the following two respondents:

\begin{abstract}
"The organisation does not consider us to be leaders, we are merely appointed to manage a production environment, where we should be working according to rules, regulations, policies and procedures. The leadership aspect of my role is secondary and to prove this; how many times has anyone in the organisation discussed my leadership competencies with me - it never happens - it is all about plant performance and production figures." (R2).

"If we were considered to be playing a crucial leadership role in the organisation we would be empowered accordingly and the results would be evident as each centre would have very effective leaders (engineers) leading their individual teams and that would translate to exceptional team performances, which in turn would be reflected on the overall performances of each centre." (R5).
\end{abstract}

Respondents added that it was important for engineers to be considered leaders because they ultimately had to lead their teams within organisations. Farr and Brazil [26] echoed this 
sentiment, stating that leadership must be a key element in advancing the engineering profession, keeping it relevant and connected. As much as technical excellence is the essential attribute of engineers, the engineers should also have in their possession team communication skills, ethical reasoning skills, contextual analysis skills, and leadership skills. Furthermore, engineers must be trained and recognised as leaders in their own rights: too often an engineer is employed for his technical competency, dismissed for having poor people skills, and promoted for his leadership and management skills [26].

The study also identified that, resulting from the perceived nonrecognition of the respondents as leaders, respondents felt that they were excluded from a great deal of training and development opportunities that would better prepare them for both their current and future leadership roles. Respondents argued that the organisation was also losing the opportunity of training engineers as a succession-planning strategy for their future roles. Current managers were previous engineers. In addition, respondents said that this missed opportunity becomes evident when the managers find themselves lacking in their leadership competencies.

\section{III.IV. Lack of leadership role clarity for the engineers}

The study highlighted that a number of respondents were uncertain about what was expected of them in their leadership roles as newly appointed engineers. This introduced an element of frustration and self-doubt, with most respondents relying heavily on their instincts and experiences to navigate their way around. This created some role ambiguity, which, according to Srikanth and Jomon [27], is defined as the lack of sufficient information availed to one, thus hindering their ability to effectively execute responsibilities. There was a distinct lack of adequate information about the processes needed to be followed for engineers' responsibilities to be effectively executed.

\section{"Leadership roles are not defined and explained when one is appointed into the position, one is appointed as an engineer, thrown in the deep end and expected to survive. I pick up the pieces of what my leadership role should be as I go along. I meet all sorts of challenges and surprises, get burnt in the process and whipped at the same time for wrong decisions that I may have taken through ignorance." (R7).}

However, the study also identified that some of the respondents had their roles clarified for them; hence, in such cases, role ambiguity was eliminated:

"I do have my key performance areas (KPAs) which I sit, discuss and agree upon with my boss at the beginning of every season, however, these seem to be changing every so often depending on the production requirements and it makes it difficult at times to manage them accordingly." (R14).
This made it a lot easier for the respondents to execute their tasks well, with a full understanding of what was expected from them as new leaders. Srikanth and Jomon [27] discussed that it is essential for role expectations to be made known to the individual, and for sufficient knowledge of activities needed to fulfil those expectations, to be provided.

\section{I I. V. Insufficient leadership skills empowerment}

The study uncovered that the respondents believed that, as much as they had the necessary technical competencies to execute their responsibilities as engineers, they were very concerned with their leadership capabilities - they felt they were not adequately empowered to effectively lead their teams. It is crucial for engineers to be empowered to fully comprehend the principles of leadership and be able to put them into practise in progressive proportions as they pursue their careers [28].

\begin{abstract}
"I have been an engineer for the past twelve years and the last time I got any leadership training was eleven years ago. I am relying on my leadership instincts and experience to lead my team and I think I am doing a good job under the circumstances. Unfortunately, my leadership experience can only take me up to a certain point and beyond that my effectiveness becomes shallow." (R6).
\end{abstract}

Leadership empowerment may be defined as a kind of resource allocation strategy that may be used to cut down the dependence of an individual or team on higher power or senior personnel. Hassan et al. [29] argued that leadership empowerment entailed sharing decision-making authority with subordinates, consulting them on critical work-related decisions; increasing autonomy, and cutting down bureaucracy which negatively impacted productivity and efficiency of the individual or team. These definitions are in line with the finding of the study.

The study further discovered that, resulting from the lack of leadership empowerment, the respondents felt de-motivated and impotent when faced with leadership issues that were difficult to deal with.

\begin{abstract}
"I have been in this position for about a year and I am still in the dark with regards to how I should be leading my team. I have no experience and I am only relying on what I pick up from my seniors and what I read from books. I get frustrated at times because the expectation is that as a qualified engineer, I should be able to effectively lead my team. My boss understands my situation though and is very helpful." (R4).
\end{abstract}

This finding was aligned with the argument by Prieto [30] that leadership empowerment is always associated with motivation; meaning that empowered employees are usually motivated enough to freely run independently with their tasks, being wellprepared to deal with any problems they may face in the workplace. 


\section{I. V I. Lack of leadership training and development}

The study revealed that many of the respondents had not been given any kind of formal leadership training or development, which made them rely on their individual instincts and experiences in trying effectively to lead their teams. This highlighted the urgent need for these respondents to be offered leadership training and development:

\section{"It is so unfortunate that I am not getting enough attention with regards to my leadership development. I always feel that I am on my own for most of the time and having a coach or a mentor would make such huge difference as I would know who to call on when the going gets tough or even when I need a bouncing board for simple and general matters." (R11).}

According to Kulkarni [31], such a need is determined by the employees' performance deficiency, and, according to the respondents, in their cases, such performance deficiencies are evident.

Farr and Brazil [26] expanded on this concept, explaining that leadership development in most industries tends be an ad hoc event, mainly practised as 'on-the-job training', which is mistakenly assumed by the seniors to be sufficient to develop the engineers to the required level with regard to their leadership competency.

The teaching processes for engineering, being a very technical field, stressed task execution over the quality of people, relationships and leadership. This makes it difficult to teach leadership principles to engineers. It therefore becomes imperative that any form of leadership training and any development programmes implemented are conducted in a manner appealing to engineering sensibilities: engineers prefer to be trained in practical and tangible skills that may be applied immediately [32].

The study also disclosed that many of the respondents felt that the non-availability of mentors and coaches to guide them in their leadership roles was a serious cause for concern. They believed that the role of mentors and coaches was essential for their leadership development: they would be obtaining guidance from a person who has 'been there and done that':

\footnotetext{
"I had been emulating my senior's leadership style of being autocratic because it worked for him and it still does. Unfortunately, I had an incident just after I had taken over the current section when this kind of leadership style backfired on me. This was because the team had been previously exposed to a very participative kind of style and there I was being autocratic. This simply highlighted my lack of leadership skills as I had failed to analyse and to understand the team dynamics before deciding on the kind of leadership style to use. I learnt the hard way." $(R 7)$.
}

\section{II. V II. Interference by Superiors}

Most of the respondents also felt that they had very little decision-making power when running their sections due to the controlling and autocratic leadership displayed by their superiors:

\begin{abstract}
"The approach from my bosses is always autocratic. This is very frustrating and demoralising and it makes me feel that my opinion is not valued, or that my decision-making capability and competency is undermined. How can l effectively lead my team when I have no authority over them? I must add though that I appreciate guidance where I need it, but what is happening is really out of the ordinary." (R2).
\end{abstract}

Coupled with that was a high level of interference by their superiors in their daily activities. This frustrated their leadership effectiveness and their general performance. Respondents could not infer the reason for such interference, whether this arose from trust issues between themselves and their seniors, or because their seniors perceived them (respondents) as lacking the necessary competencies.

\begin{abstract}
"We are micro-managed right to the smallest decision that one has to make. This is very demoralising and I wonder how the organisation expects us to grow and become good decision makers in the future if this is the kind of culture that dominates." (R13).

"My position feels like it has been downgraded, as a result my team has lost confidence in me because they know that I can hardly make any decisions. Every time a decision has to be made I have to consult with my boss, very frustrating." (R3).
\end{abstract}

According to the respondents, this situation was a typical case of micromanagement which, according to literature, has seriously negative outcomes on the performance of the affected individuals and teams. Rajkumar et al. [33] defined micromanagement as the process of closely observing every step or activity being performed by the employees, making sure that they know that the boss is watching them at all times. Micromanaging also entailed excessive examination of work being done, planning of minor details for the teams, and keeping track of the time employees were occupied at work or when they were found to be away from their work stations. Furthermore, micromanagement may simply be defined as the process of closely evaluating people and controlling their work activities, with the superior making all the necessary decisions [34].

Wanjau and Kyongo [35] added that micromanagement interfered with employees' performance and productivity, resulting in massive hidden costs, either direct or indirect, to both the employees and the organisation. The above-mentioned researchers added that, regardless of the motive for micromanaging, this behaviour had the potential effect of creating resentment, employee disengagement, inhibition of 
innovation, and the destruction of trust between the parties involved. This prompted the comment from the respondents that their supervisors did not trust them sufficiently to competently execute their leadership responsibilities.

Furthermore, the study identified that the respondents acknowledged and appreciated that micromanagement did have a place in the workplace.

\section{"I have been allowed to make mistakes and I have learnt a lot from them. My boss' intervention is critical in ensuring that I am still on the right track and I am happy for him to step in as and when required." (R8).}

There are instances when this style may be used effectively. Delgado et al. [34] concurred with this finding, arguing that leaders should not completely disregard micromanagement, stressing that there were instances when it had its role in the workplace. Rajkumar et al. [33] also supported this argument, stating that micromanaging may be beneficial to organisations when the manager's interference may be required to enhance productivity. This may arise when employees are inexperienced or technically incapable of performing their activities.

\section{III.VIII. Lack of exposure to relevant business aspects}

The study identified that the majority of the respondents believed they were not sufficiently exposed to some of the important business aspects of the organisation: this deprived them of the critical understanding of the complete value chain.

\begin{abstract}
"It is critical to expose the engineers to other business centres so that they can get a feel of how others work and to experience the different challenges faced by others. A better understanding of the overall business concept completely changes a person's mentality of doing certain things." (R19).
\end{abstract}

Respondents argued that, in some instances, this impacted on their decision-making abilities: they may not have the full understanding of the organisational vision, or the way in which their decision would impact on the next internal stakeholder. Respondents further mentioned that the tendency was for one to be left to concentrate on his 'silo', often failing to synchronise with the organisation's vision for the future.

\begin{abstract}
"I feel that we are currently working in our own little silos. I have no full appreciation of certain business aspects and this confines my lateral thinking. I eventually make decisions considering only what affects my immediate surroundings and fail to look at the bigger picture." (R18).
\end{abstract}

The term 'silo' mentioned above defines internally focused organisational units or divisions, in which insufficient or no attention is given to external relationships. Common features of silos are communication breakdown between divisions, less cooperation between division members and other stakeholders, and the development of unhealthy relationships between the divisions. The consequences of the existence of silos are that the organisation struggles to achieve the desired business outcomes, the misalignment between the divisions having a huge effect on the overall performance [36].

Cilliers and Greyvenstein [37] explained that silos were not a tangible feature in organisations - they reside in the minds of employees who have a common impression of their reality. To the employees, silos provide safety and comfort by isolating the others who are perceived to be outsiders. The outcome was the creation of barriers that hugely affect the overall performance and ultimately the productive culture of the organisation. The study also identified that the respondents from the various centres seemed to be disconnected from one another. Engineers and their networking were very limited: as a result, information-sharing and collaboration were non-existent.

\section{IX. Lack of Resources}

The study identified that there were many frustrations found in respondents emanating from the shortage of skilled labour to strengthen their teams:

\begin{abstract}
"The shortage of labour is very demoralising; we are expected to produce more with very few people. Anyway, in my case I believe this is where my leadership effectiveness is being tested because as a leader, I need to influence my team to achieve good results, regardless of the circumstances. It is very challenging though, I must add." (R12).
\end{abstract}

When positions became vacant and could not be filled, this affected all the engineering disciplines in the organisation as one respondent explained:
"The most important thing in my opinion during such times is the availability of skilled labour. The skilled workforce will produce excellent results in everything they touch, resulting to good overall performances which is exactly what the organisation needed to sustain its operations. Training also serves as a motivator as it gives the indication that the organisation cares about the development of its employees and to a certain degree staff turn-over gets improved." (R3).

Respondents explained that it was extremely difficult to recruit suitably qualified and experienced technical people, ranging from artisans, technicians, technologists, right to the engineers.

Mateus et al. [38] concurred with the above statement, stating that organisations found that artisans and engineers' positions remained the most difficult positions to fill. This affected the majority of industries in the country as a whole. They further argued that South Africa's persistent skills' shortage was being complicated by the lack of proper technical skills' training, which was largely attributed to the decline of the apprenticeship 
and learnership systems that were known to produce excellent tradesmen in the past. Also, the lack of experience from the people who had acquired some form of technical training made it difficult for industry to integrate such individuals into their organisations.

Organisational performance excellence and sustained growth cannot be achieved without the efficient performance of skilled workers. Skilled workers are an important lever for accelerating production and human development, as well for adding value by bringing in improved job knowledge, transferring knowledge to other workers, upholding organisational culture and cultivating more positive attitudes in the organisation towards profit orientation [39]. This can only mean that the incompetency levels in the organisation further spiral downwards, affecting the organisation's ability to enhance its productivity and expand its wealth [40]. Putta [41] supported this finding, maintaining that it was unfortunate that training budgets in most organisations were the first budgets to be suspended when these organisations were going through difficulties.

The embargo on employment was identified as another serious issue of concern. The respondents mentioned that vacancies were not being filled to save costs. Certain sections were operating with only fifty per cent of their labour complement. Saddington [42] expanded on the above, saying that the current economic climate has subjected many organisations to tremendous pressure to keep labour costs low by reducing staff numbers and benefits, whilst simultaneously increasing performance and productivity.

\section{III.X. Self-Development of leadership skills}

The study identified that most of the respondents were currently not attempting to develop their leadership skills and were relying on the organisation to provide the necessary training and development. This was contrary to the notion that the emerging knowledge society imposes new demands on individual leaders to continuously develop their leadership and management competencies to remain abreast, relevant, and adaptive to work environment challenges [43].

\section{"I got disappointed when certain individuals were chosen for the development programme in 2015 and I was left out. No explanation was given to me for my exclusion and this de-motivated me. Right now, I am not in a position to register for any leadership course because the company will not pay for my fees and I will not be given any time off to attend to my studies." (R5).}

Farr and Brazil [26] explained that successful engineers become successful because of the continued demonstration of their technical excellence, together with certain management abilities. For engineers to become effective and respected leaders, they must continue developing and refining their leadership competencies, which unfortunately was not the case with some of the respondents.

The study also identified that a number of respondents had decided to take control of their individual careers, taking proper steps to develop themselves. These respondents had opted to enrol for post-graduate leadership programmes without the involvement and assistance of the organisation as they hoped that such would open professional doors for them as described below:

"I realised the need to privately enrol for a post graduate leadership qualification because nothing was forthcoming from the organisation and yet I know myself to be very passionate about leadership. I am hoping my qualifications will open doors for me in places where my leadership competency will be valued." (R2).

Another added:

"I am looking beyond this organisation; hence I am empowering myself with the necessary leadership skills. I am currently doing a post graduate qualification in leadership and it is a great pity that I currently feel that I am not considered as a leader in my current role, yet I know I have a lot to offer." (R1).

\section{FINAL THOUGHTS AND RECOMMENDATIONS}

The aim of this study was to explore the leadership effectiveness of engineers at a company in the sugar industry in South Africa. The study highlighted that the leadership effectiveness of engineers was severely compromised by several issues that they faced as they endeavored to effectively perform their leadership roles. The issues identified were as follows:

- The mode of leadership practised by respondents' seniors.

- The perceived lack of recognition of the engineers' leadership status or lack of support for the engineer's role by the organisation.

- The ambiguity of the leadership role for the engineers.

- The lack of sufficient empowerment of leadership skills for the engineers.

- The micromanagement practices applied to the engineers by their seniors.

- The lack of networking and collaboration between the centres and divisions.

- The shortage of resources (financial and human resources).

The first area of leadership improvement on which the respondents needed to focus was the understanding of their own 
way of leading others, before they could try to understand the leadership of other people around them. Failure to do this could lead to the respondents vacillating, being easily influenced by others, resulting in unnecessary disagreements and conflicts between the parties involved.

Role-balancing was identified as another area of improvement. The respondents expressed that, owing to the business being a productive environment, and with respondents coming from a technical-based background, they tended to focus more on technical and managerial issues, resulting in their leadership roles lagging behind. Serious improvements of the balancing of the roles were essential for the respondents to be able to cover the complete role profile for the engineers' position. This would certainly enhance their leadership effectiveness.

The study also identified a lack of assertiveness from the majority of the respondents. This was evident from the issues mentioned around role ambiguity. It appeared that the respondents expected to be told about every small detail of their leadership role. Very little initiative and effort was seen on their part with regard to proactively making more enquiries about the role profile of the engineers' position. This area certainly needed to be improved on, assertiveness being one of the key characteristics of effective leaders.

Leadership skills' empowerment was identified as an area demanding urgent attention. It is obvious that without proper empowerment the respondents will never be able to lead effectively; there will always be someone pulling the strings behind the scenes; with the workplace being dominated by the unfavoured autocratic and micromanagement styles. The respondents conceded that this was a two-way affair, in which both the company and the respondents needed actively to play a role in addressing this problem. Under the current economic climate, however, it was obvious that the company's contribution might be limited, however, there were other means such as mentoring and coaching that could be utilised to help improve the situation. More respondents could also embark on self-development initiatives as some of them had already done.

The respondents mentioned that there was a serious lack of networking and collaboration within the various centres of the organisation, which emanated from the 'silo' mentality that existed, even though the organisation was promoting a 'one company philosophy' theme. Improving this aspect would ensure that there was effective communication between the centres, effective sharing of information, effective sharing of resources and experiences, and a better understanding of the overall business value chain, which would enhance decisionmaking for the respondents, taking into account the bigger organisational picture, leading to improved performances and productivity.

Recommendations include developing a formal leadership development programme. In most cases these programmes take place in a classroom environment in which seminars and conferences are held to discuss leadership principles and theories [44]. It is important that such programmes be supported and sponsored by senior leadership of the organisations. Job assignments could also assist leaders in learning and gaining experience about building teams, becoming better strategic thinkers, and gaining valuable persuasion and influencing skills.

Having the senior executives of the organisation sharing their experiences and anecdotes with developing leaders could go a long way towards entrenching the organisational culture, values, and corporate identity. In addition, executive coaching may be an excellent vehicle for knowledge transfer, as well as action learning. Networking development for the respondents may be achieved through action-learning projects used in leadership-development seminars. Such projects will allow the engineers to strengthen their personal networks, as well as to increase their leadership, innovation and problem-solving capacities. Companies such as Motorola have successfully used such approaches [44].

\section{CONCLUSION}

Improving the leadership effectiveness of engineers may result in improved effectiveness of teams, which ultimately would translate to higher productivity levels, benefiting the organisation and all other stakeholders. It is hoped that once superiors have a full understanding of the identified gaps (such as the need for formal leadership programmes, the need for job assignments, the need for executive coaching and action learning, as well as the need for networking), they will initiate appropriate actions to ensure that the leadership effectiveness of the engineers is effectively addressed to the benefit of the engineers, their teams, the organisation, and all other stakeholders. This is especially relevant as it is no longer wise to see the success of companies as being predicated on physical resources alone and it is hoped that this study will draw attention to the significant role that the leadership capabilities of engineers (and the development thereof) can have on overall organisational success.

\section{REFERENCES}

[1] J. Crawford, Irrigation, South African Sugar Journal, 11(2), 2015, 1 - 68.

[2] C. Goko, Business Day (late Final), Companies and Markets. [Online], 2016,

Available at: https://www.businesslive.co.za/bd /companies/land-and-agriculture/2016-11-07-tongaathulett-expects-interim-earnings-growth/ [Accessed 15 November 2016].

[3] U. Tiwari, A study on employee morale and its impact on employee efficiency. International Journal of Research in Management \& Technology, 3(11), 2014, 8-14.

[4] C. N. Gerwel Proches, and S. Bodhanya, An analysis of 
multi-stakeholder interactions in the sugar industry using a social complexity framework. Problems and Perspectives in Management, 11(4), 2013, 77-85.

[5] C.N. Gerwel Proches, and S. Bodhanya, Exploring stakeholder interactions through the lens of complexity theory: lessons from the sugar industry. Quality and Quantity: International Journal of Methodology, 49(6), 2015a, 2507-2525.

[6] C.N. Gerwel Proches, and S. Bodhanya, An Application of Soft Systems Methodology in the Sugar Industry. International Journal of Qualitative Methods, 14, 2015b, $1-15$.

[7] C.N. Gerwel, S. Hildbrand, S. Bodhanya, and C. Bezuidenhout, Systemic approaches to understand the complexities at the Umfolozi and Felixton mill areas, Proc. of the 84th Annual Congress of the South African Sugar Technologists' Association (SASTA), Durban, South Africa, 2011, 177-181.

[8] S. Hildbrand, and S. Bodhanya, Exploring the complexity of sugarcane supply chains via systemic approaches, Kybernetes, 46(2), 2017, 310-329.

[9] M. I Shongwe, C. N Bezuidenhout, M. S Sibomana, T. S Workneh, S. Bodhanya, and V.V Dlamini, Developing a Systematic Diagnostic Model for Integrated Agricultural Supply and Processing Systems, Systems, 7(1), 2019, 15.

[10] H. Shekari, Y. Taft, and M. Z Nikooparvar, Promoting Leadership Effectiveness in Organizations: A Case Study on the Involved Factors of Servant Leadership. International Journal of Business Administration, 3(1), 2012, 54 - 65.

[11] R. J Allio, Leaders and leadership - many theories, but what advice is reliable?. Strategy \& Leadership, 41(1), 2012, 4 - 14.

[12] A. McCarthy, Leading During Uncertainty and Economic Turbulance: An Investigation of Leadership Strengths and Development Needs in the Senior Irish Public Sector. Advances in Developing Human Resources, 16(1), 2014, 54-73.

[13] D.D Green, and J. McCann, Benchmarking a leadership model for the green economy. Emerald Insight Benchmarking: An International Journal, 18(3), 2011, 445-465.

[14] M. Döös, P. Johansson, and L. Wilhelmson, Beyond being present: learning oriented leadership in the daily work of middle managers. Journal of Workplace Learning, 27(6), 2015, 408 - 425.

[15] M. K. Sharma, and S. Jain, Leadership Management: Principles, Models and Theories. Global Journal of Management and Business Studies, 3(3), 2013, 309-318.

[16] P. Spicker, Leadership: a perniciously vague concept. International Journal of Public Sector Management, 25(1), 2012, 34 - 47.

[17] R. Lopez, The Relationship between Leadership and Management: Instructional Approaches and its Connections to Organizational Growth. Journal of Business Studies Quarterly, 6(1), 2014, 98-112.

[18] N. Singh, and S. A Bodhanya, Followership in contemporary organisations: A South African Perspective, Journal of Contemporary Management, 10(1), 2013, 498-516.

[19] A.H Alkahtani, The Influence of Leadership Styles on Organizational Commitment: The Moderating Effect of Emotional Intelligence. Business and Management Studies, 2(1), 2016, 23 - 34.

[20] C. L Giltinane, Leadership styles and theories: Nursing Standard. Art and Science - Professional issues, 27(41), 2013, 35 - 39.

[21] A. Algahtani, Are Leadership and Management Different? A Review. Journal of Management Policies and Practices, 2(3), 2014, 71-82.

[22] S. G Willcocks, Exploring leadership effectiveness: Nurses as clinical leaders in the NHS. Leadership in Health Services, 25(1), 2012, 8 - 19.

[23] J. W, Creswell, Research Design. Qualitative, Quantitative and Mixed Methods Approaches. 4th ed. (Dorchester: SAGE Publishers, 2014).

[24] B. Hancock, K. Windridge, and E. Ockleford, An Introduction to Qualitative Research. National Institute for Health Research (The NIHR Research Design Service for the East Midlands),2009, 4 - 37.

[25] G. Ekaterini, The Impact of Leadership Styles on Four Variables of Executives Workforce. International Journal of Business and Management , 5(6), 2010, 3 - 16.

[26] J. V Farr, and D. M Brazil, Leadership Skills Development for Engineers. Engineering Management Journal, 21(1), 2009, 3 - 8.

[27] P. B Srikanth, and M. G Jomon, Role ambiguity and role performance effectiveness: Moderating the effect of feedback seeking behaviour. Asian Academy of Management Journal, 18(2), 2013, 105- 127.

[28] B. Mendelsohn, Transforming Engineers into Engineering Leaders. Materials Today, 12(11), 2009, 6.

[29] S. Hassan, R. Mahsud, G. Yukl, and G.E Prussia, Ethical and empowering leadership and leader effectiveness. Journal of Managerial Psychology, 28(2), 2013, 133 146.

[30] B. Prieto, Establishing and Building Leadership Skills. Leadership and Management in Engineering, 13(3), 2013, 209 - 211.

[31] P. P Kulkarni, A Literature Review On Training \& Development And Quality Of Work Life. Journal of Arts, Science \& Commerce, 4(2), 2013, 136 - 143.

[32] A. E Simpson, and G. J Evans, A Summer Leadership Development Program for Chemical Engineering Students. Journal of Leadership Education, 11(1), 2012, 222 - 232.

[33] M. Rajkumar, A. Venkataraman, and M. Gayathri, Micromanagement: An Employee's Adversary. European Journal of Business and Management, 8(18), 2016, 38 - 43.

[34] O Delgado, E. M Strauss, and M. A Ortega, Micromanagement: When to avoid it and how to use it effectively. American Journal of Health-System Pharmarcy, 72, 2015, 772 - 776. 
[35] M. N Wanjau, and J. Kyongo, Contribution of Motivational Management to Employee Performance. International Journal of Humanities and Social Science, 3(14), 2013, $219-239$.

[36] H. Vatanpour, A. Khorramnia, and N. Forutan, Silo Effect a Prominence Factor to Decrease Efficiency of Pharmaceutical Industry. Iranian Journal of Pharmaceutical Research, 12, 2013, 207 - 216.

[37] F. Cilliers, and H. Greyvenstein, The impact of silo mentality on team identity: An organisational case study. SA Journal of Industrial Psychology, 38(2), 2012, 1 - 9.

[38] A. D Mateus, C. Allen-Ile, and C. G Iwu, Skills Shortage in South Africa: Interrogating the Repertoire of Discussions. Mediterranean Journal of Social Sciences, 5 (6), 2014, 63 - 73.

[39] N. Tahir, I. K Yousafzai, S. Jan, and M. Hashim, The Impact of Training and Development on Employees Performance and Productivity A case study of United Bank Limited Peshawar City, KPK, Pakistan. International Journal of Academic Research in Business and Social Sciences, 4(4), 2014, 86 - 98.

[40] M. C. Tshilongamulenzhe, Enunciating the skills development challenge facing South Africa. International Journal of Law and Social Sciences, 1(1), 2012, 30 - 35.

[41] H. Putta, Impact of recession on training. Journal of Business and Management, 16(9), 2014, 42 - 44.

[42] J. Saddington, Keeping talent in tough times. [Online] Available at: http://www.thormsonreuters.co.zn/files/2011/02/Manage ment keeping-talent-in-tough-times [Accessed $13 \quad 10$ 2016].

[43] A. Louys, D. Hernandez-Leo, J. Schoonenboom, R. Lemmers, M. Perez-Sanagustin, Self-Development of Competences for Social Inclusion Using the TENCompetence Infrastructure. Educational Technology \& Society, 12(3), 2009, $70-81$.

[44] D. V. Day, and S.M Halpin, ALeadership Development: A Review of Industry Best Practices. U.S. Army Research Institute for the Behavioral and Social Sciences, 2001, pp. $1-68$. 